\title{
Trajetórias juvenis: processos de autonomização de jovens cariocas e desigualdades sociais
}

\section{Clarice Peixoto}

\section{(2) OpenEdition \\ 1 Journals}

Edição electrónica

URL: http://journals.openedition.org/aa/823

DOI: $10.4000 /$ aa. 823

ISSN: 2357-738X

\section{Editora}

Programa de Pós-Graduação em Antropologia Social (UnB)

\section{Edição impressa}

Data de publição: 1 junho 2010

Paginação: 175-198

ISSN: 0102-4302

\section{Refêrencia eletrónica}

Clarice Peixoto, «Trajetórias juvenis: processos de autonomização de jovens cariocas e desigualdades sociais», Anuário Antropológico [Online], v.35 n.1 | 2010, posto online no dia 12 outubro 2015, consultado o 28 abril 2021. URL: http://journals.openedition.org/aa/823 ; DOI: https://doi.org/ $10.4000 / a a .823$

\section{(c) (i) (9)}

Anuário Antropológico is licensed under a Creative Commons Atribuição-Uso Não-Comercial-Proibição de realização de Obras Derivadas 4.0 International. 


\title{
Trajetórias juvenis: processos de autonomização de jovens cariocas e desigualdades sociais*
}

\author{
Clarice Peixoto \\ Departamento de Ciências Sociais/UERJ
}

Os processos de autonomia ${ }^{1}$ dos jovens brasileiros se diferenciam conforme seus pertencimentos sociais, sendo múltiplas as estratégias escolares que eles utilizam para conquistar certa independência financeira familiar. Apesar das dificuldades de acesso ao ensino superior, a maioria dos jovens que conclui o ensino médio pretende obter um diploma de nível universitário, pois ele é considerado o melhor veículo de acesso ao mercado de trabalho (melhores chances em um mercado cada vez mais exigente) e com níveis salariais mais elevados. Ainda que sejam minoritários no mundo universitário, os jovens das camadas populares vêm se tornando significativamente mais numerosos do que há 10 anos, consequência da criação de políticas afirmativas para a juventude voltadas para o ingresso na universidade. ${ }^{2}$

Para o atual sistema educacional brasileiro, os jovens entre 18 e 24 anos já deveriam ser universitários, ${ }^{3}$ mas os indicadores sociais do IBGE (2008) apontam para uma grande defasagem escolar, pois "pelos critérios de adequação idade/nível de ensino, esses jovens deveriam estar cursando a universidade. No entanto, 57,6\% estavam cursando o ensino fundamental, médio ou outros (o que compreende pré-vestibular, supletivo e alfabetização de adultos) e 42,4\% estavam em cursos de graduação ou pós-graduação” (Indicadores Sociais, 2008:48).

As razões para estas altas taxas de defasagem são: a) uma "parcela considerável das crianças ingressa na juventude com elevada defasagem educacional, tanto do ponto de vista quantitativo quanto em termos qualitativos" (Castro et al., 2009:92); b) os jovens têm, cada vez mais, que conciliar estudo e trabalho, esta é a realidade de $26,4 \%$ dos brasileiros que tinham entre 15 e 17 anos, e de $17,7 \%$ daqueles que tinham de 18 a 24 anos (idem:115). Interessante observar que há mais jovens de 15-17 anos estudando e trabalhando do que de 18-24 anos. Isto nos leva a supor que, dentre estes últimos, aqueles que são universitários recebem bolsas de estudo - que não são consideradas como trabalho assalariado - ou recebem maior apoio material familiar. Outro dado importante é que, em 2007, 73\% dos jovens entre 15-17 anos não trabalhavam nem estudavam, enquanto apenas $13,8 \%$ do grupo de 18-24 anos se enquadravam nessa categoria (ibidem:115). 
Se é grande a proporção dos jovens entrevistados na nossa pesquisa que atribuem maior valor ao diploma universitário, outros preferem optar por diplomas de curta duração, viabilizando assim uma rápida inserção no mercado de trabalho, ainda que menos remunerados. São diplomas técnicos de nível médio (informática, mecânica etc.) ou cursos de formação nas áreas esportiva ou artística, ${ }^{4}$ alguns deles sem o reconhecimento oficial do diploma.

Para muitos desses jovens de baixa renda, o curso universitário nem sempre é a opção imediata para a qualificação profissional; eles procuram inicialmente uma formação de nível médio ou técnico. Este foi o percurso escolhido por 10 dos nossos entrevistados: ${ }^{5}$ informática, mecânica, contabilidade, inglês ou espanhol, desenho e dança étnica foram as qualificações realizadas. ${ }^{6}$ Vulneráveis às exigências de um mercado de trabalho instável e tendente à informalidade, e pressionados pelas famílias para se tornarem independentes, esses jovens investem em modalidades de capacitação que aceleram a emancipação familiar. Para a maioria dos jovens do meio popular, os estudos universitários ou as especializações técnica, esportiva e artística estão associados à conquista da independência financeira em relação aos pais, mas principalmente à possibilidade de ascensão social.

A intenção deste artigo é analisar as trajetórias de jovens estudantes, focalizando nas formas de construção da autonomia e no apoio familiar recebido (ou não) ao longo desse processo, pois a transição para a vida adulta é penosa e implica a construção de projetos para o futuro que irão determinar as vidas profissional e familiar. As escolhas dos caminhos a percorrer são, em geral, condicionadas pelo pertencimento social e o nível de instrução de cada indivíduo, fatores fundamentais na determinação do tempo destinado à formação e à entrada no mundo do trabalho. Para Pais (1996), essa passagem à vida adulta "resulta da ação de um conjunto de fatores que devem ser concebidos como um sistema" (:197) pois, ao analisarmos as trajetórias juvenis, não podemos desprezar os contextos de que lançam mão os jovens para tomar as suas decisões. Assim, com o tempo, eles reúnem um conjunto de escolhas ou alternativas possíveis de

projectos de vida, a que geralmente se associam determinadas estratégias - individuais e sociais -, que se perfilam de forma muito diferenciada e tem significações individuais e sociais diferentes, não apenas porque essas escolhas aparecem associadas a diferentes projectos de futuro, mas também a diferentes passados que elas implicam ao nível de realidades expectativadas (idem:198).

Entendemos, assim, que a juventude não pode ser analisada de maneira uniforme, pois ela apresenta diferenciais em função dos pertencimentos sociais dos jovens. 
Juventude é uma categoria que tem sido analisada histórica e socialmente como uma fase da vida, cujas fronteiras etárias delimitam o ciclo da vida. Não pretendemos aqui retomar esse debate. Consideramos juventude tal como Galland (1997), Pais (1996) e Heilborn (2006) a veem: como um processo social de transição para a vida adulta, ou seja, “o conjunto de pequenos rituais de passagem constitui o processo de transição para a vida adulta” (Heilborn, 2006:42). Nesse sentido, podemos entender que o prolongamento da escolarização leva os jovens a viverem mais tempo na casa dos pais, retardando assim a conquista de uma vida financeira independente. Os trabalhos de Galland (1997), Cicchelli (2000, 2001), Pais (1996), Ramos (2006) têm apontado para os efeitos do prolongamento dos estudos na vida dos jovens: o adiamento da saída da casa dos pais e da constituição de uma vida familiar própria.

No entanto, para estudar as estratégias de que lançam mão os jovens cariocas para continuar estudando, é preciso considerar o processo de expansão urbana do Rio de Janeiro, que expulsou as camadas populares para os bairros mais distantes, ou para os morros da cidade. Essa urbanização desordenada do território provocou um processo de segregação espacial, criando uma periferização social que é um reflexo de condições socioeconômicas diferenciadas: ${ }^{7}$ a infraestrutura de transportes é mais precária e a educação oferecida é de menos qualidade. Assim, $18,9 \%{ }^{8}$ da população carioca vivem em comunidades faveladas, ${ }^{9}$ situadas nas zonas sul, norte, oeste e nos subúrbios. Essa estratificação social é de grande visibilidade na paisagem das zonas sul e norte ${ }^{10}$ pois, embora mais bem servidas por transportes, apresentam desigualdades brutais nos tipos de moradia e nas condições de saneamento básico, reflexo da ausência de políticas públicas voltadas para as populações de baixa renda.

\section{Aspectos metodológicos}

As análises aqui apresentadas se baseiam em entrevistas semidiretas realizadas com 24 jovens estudantes de 17 a $27 \operatorname{anos}^{11}$ que vivem na região metropolitana do Rio de Janeiro e em municípios limítrofes. Entrevistamos um mesmo número de rapazes e moças, sendo que $1 / 3$ deles pertence às camadas médias cariocas, como contraponto comparativo.

A seleção dos jovens não foi aleatória, já que pretendíamos comparar jovens de camadas sociais diferenciadas. A escolha baseou-se, assim, menos no nível de instrução dos pais e muito mais em vários elementos de 
configuração social que, no Brasil, são importantes indicadores de análise, permitindo melhor compreender o cenário no qual vivem esses jovens.

Critérios de seleção: pertencimento social e lugar de residência (jovens de camadas populares e de camadas médias, vivendo em bairros pobres e ricos); ser estudante (de diversos níveis, inclusive técnico e artístico) ou não, e as razões do abandono; ser dependente economicamente dos pais ou de um membro da família. O objetivo era ter um amplo panorama de situações.

O roteiro de entrevista semidiretiva compreendia várias questões sobre as condições materiais (propriedade ou não do imóvel e as condições de moradia: número de cômodos e de pessoas vivendo na casa, profissão dos pais e número de pessoas trabalhando, localização do bairro de residência, meios de transporte e tempo de deslocamento etc.) e sobre os apoios familiares afetivos e materiais (estímulo, financiamento dos estudos, mesada, ajuda nas tarefas de casa etc.).

A maioria dos jovens entrevistados ainda mora na casa dos pais, ou vive com um deles quando estes são divorciados ou viúvos (20). São portanto solteiros, estudam, e muitos trabalham para financiar os estudos, o transporte e o lazer. São 12 rapazes e 12 moças e, à exceção de quatro que abandonaram os estudos, os demais seguem buscando uma formação profissional mais qualificada via inserção nos quadros universitários.

O que propomos neste artigo é uma comparação entre as diferentes situações sociais dos jovens cariocas e as circunstâncias que contextualizam o processo de emancipação financeira. Pretendemos explorar o impacto das condições materiais (bairro de moradia e tipo de habitação, meios de transporte e tempos de deslocamento etc.) e afetivas (apoio dos pais, ajuda nas tarefas domésticas etc.) nas escolhas e nos projetos futuros de cada um.

\section{A diversidade social das condições de moradia: espaço e tempo de trabalho escolar}

A análise do nível de instrução dos pais mostra que existe certa homogamia educacional entre os cônjuges: de um lado, pais e mães que nem chegaram a concluir o ensino fundamental ou que não terminaram o ensino médio; de outro, pais que têm diploma universitário. ${ }^{12}$ As qualificações profissionais dos pais e das mães desses jovens mostram que as desigualdades têm ainda um efeito perverso: 
uns(umas) estão inativos(as) - desempregados(as) ou aposentados(as) - recebendo parco auxílio desemprego ou baixas aposentadorias. Afora isso, várias são as mães que não trabalham (11), independentemente do nível de instrução: entre as donas de casa, algumas têm diploma universitário sem nunca ter exercido a profissão, e outras são semianalfabetas. Há também trabalhadores(as) autônomos(as) - bombeiros, pedreiros, empregadas domésticas, vendedoras a domicilio - que, nos atuais tempos de desemprego e mal qualificados para o mercado de trabalho, entram na competição em desvantagem, sendo mal remunerados. A maioria desses pais e mães exerce atividades de nível técnico: contadores, técnicos em eletricidade ou em segurança do trabalho, protética, secretária, professoras primárias, gerentes. Dentre os que têm diploma universitário, destacam-se advogados(as), médicos(as) ou enfermeiros(as) e engenheiros(as). Muitos trabalham no setor público.

No universo familiar, os pais enunciam valores, criam regras e dispositivos para exercer o papel educativo e, com isso, estimulam os filhos a terem mais responsabilidades e amadurecimento nas escolhas e nas decisões (Cicchelli, 2001). Os pais diplomados procuram matricular seus filhos nas melhores escolas (privadas), em cursos de línguas e informática, acompanhando de perto a trajetória escolar e universitária dos filhos. Os pais de origem modesta têm menos instrução e mais dificuldade para acompanhar os estudos dos filhos que, em desvantagem, percebem apenas a importância do diploma universitário para a conquista de melhor lugar no mercado de trabalho.

As origens sociais desses jovens são muito distintas. Consideramos que as condições materiais da moradia e o espaço privado - o bairro onde moram, o número de cômodos etc. - permitem melhor compreender o cenário no qual eles vivem.

Como foi dito acima, a maioria das famílias mora em bairros das zonas norte e oeste, somente três vivem na zona sul. Várias (12) se dizem proprietárias do imóvel onde vivem. Cinco não são exatamente proprietárias, pois moram em comunidades faveladas: são posseiras; três moram em casas ou apartamentos cedidos por parentes e os consideram como propriedade familiar. As demais famílias são locatárias. A propriedade do imóvel não implica condições de moradia mais adequadas. Grande parte desses jovens divide o quarto com irmãos, sobrinhos e até com a mãe; carecem, assim, de espaço e tranquilidade para estudar.

O caso de Mônica, que divide o quarto com a irmã divorciada e o sobrinho pequeno, é exemplar, pois só estuda em casa quando a criança dorme: "Ele me atrapalha muito. Eu estudo na rua, na faculdade, na biblioteca da cidade" (22 anos, estuda enfermagem, mora com os pais, o irmão, a irmã e o sobrinho em um apartamento de sala e dois quartos). Em geral, os jovens das camadas mais favorecidas têm um quarto só para si ou, quando muito, dividem com um irmão. Mas para 
Rogério, que vive com os pais, a irmã e o primo em uma casa de três quartos e duas salas, tendo um quarto só para ele, isto nem sempre garante a tranquilidade necessária, pois “minha casa é uma verdadeira loucura, porque é uma família muito grande. O tempo inteiro tem gente chamando, entrando, é um entra-e-sai terrível! Prefiro estudar na mesa da cozinha, de meia-noite em diante, rende melhor e é um silêncio absoluto" (23 anos, curso de Letras).

Maria divide o quarto com a mãe e relata as dificuldades que enfrenta para estudar em casa (22 anos, pais divorciados, estuda história). Ela não é a única, Daniela divide o quar to com a irmã mais nova, trabalha o dia inteiro e cursa a universidade à noite (20 anos, faculdade particular de jornalismo). Como não para em casa, estuda no próprio trabalho: "em casa, só mesmo na semana de provas, quando me tranco no quarto e peço para ninguém abrir a porta".

Se uns preferem estudar fora de casa (em bibliotecas, no trabalho) ou em espaços coletivos da casa (sala, copa), outros consideram o seu quarto o lugar mais adequado e tranquilo. Sabemos que a vida familiar é regida por regras parentais sobre o uso dos espaços comuns (e algumas vezes dos privados) e os ritmos da coabitação (horários). Se os espaços comuns são administrados segundo uma ordem doméstica, em geral determinada pela mãe, o quarto é o espaço privado de cada um e onde é permitida certa desordem (Ramos, 2006).

Sobre ordem-desordem, não é de estranhar que as tarefas domésticas sejam desempenhadas sobretudo pelas mulheres e divididas entre mãe e filhas, quando não há empregada doméstica. Se, por um lado, as mães tomam a si a responsabilidade pela ordem doméstica, por outro, as filhas não a consideram como uma obrigação sua; elas a assumem para não sobrecarregar a mãe: uma solidariedade de gênero, já que "a capacitação para uma determinada tarefa não é produzida originalmente pela natureza dos sexos, mas pela cultura que simboliza as atividades como masculinas ou femininas", como afirma Heilborn (1995: 2). Nesse sentido, Mônica diz que:

As tarefas domésticas não se dividem em coisas de menina e coisas de menino. Isso já caiu há muito tempo. São valores impostos pela sociedade. Só que a sociedade evoluiu e meus pais, não, e meu irmão, como foi educado com as coisas de menino, ele suja e não limpa! Só quando ele está de bom humor. Roupa nem pensar! Acho muito estranho, não gosto disso. Acho uma criação muito errada: separar as coisas de menina e as coisas de menino.

Outras jovens, como Patrícia (20 anos), cuja família atravessa momentos de grande dificuldade econômica, ${ }^{13}$ não têm a mesma visão de Mônica sobre a distribuição das tarefas entre os membros da família. É ela quem faz todos os trabalhos 
domésticos antes de ir para a universidade e não considera isto uma obrigação: ajuda a mãe que trabalha o dia inteiro e justifica o pai desempregado: "Não sou responsável, faço porque tenho tempo e, quando alguém tem, também ajuda. Meu pai, às vezes, ajuda a lavar a roupa".

Fougeyrollas-Schwebel assinala que "contrariamente às perspectivas otimistas que prevaleciam nos anos 1960, quando se pensava que o desenvolvimento da atividade profissional feminina acarretaria novas divisões das tarefas, é forçoso constatar que houve pouca evolução na partilha das tarefas entre homens e mulheres. 'O pai sempre vê sua atividade profissional como a dominante de suas preocupações, e a presença de filhos tem pouca incidência na organização de sua vida cotidiana'” (1994: 341).

É bem verdade que na sociedade brasileira os homens parecem não considerar que as tarefas domésticas sejam também de sua responsabilidade; para eles, o mundo masculino continua sendo a rua, o feminino, a casa (DaMatta, 1987). No entanto, as mulheres estão igualmente inseridas no mundo do trabalho e, assim, também circulam na rua. É o que pensa Rogério quando diz: "o meu problema é que eu e o meu pai, a gente não para em casa, a gente sai de manhã cedo e só volta tarde da noite. Então, acaba que as duas ficam em casa, também não tem muita coisa pra fazer, lavar roupa é botar na máquina, não tem problema”. Ele insiste em apontar a falta de habilidade masculina para o exercício do trabalho doméstico, cabendo aos homens os serviços mais "pesados", ou quando muito, organizam seu espaço pessoal (quarto). Diz ele:

Minha casa é pequena. Não tem muito trabalho, a não ser quando é a grande faxina de fim de mês: arrasta móvel, limpa azulejo, sobe escada e troca lâmpada. Esse serviço sempre sobra pra mim, porque sou muito alto. Se tiver alguma coisa que levar para consertar é o meu cargo ou do meu pai. Mas o dia-a-dia mesmo da casa é basicamente a minha irmã e a minha mãe (23 anos, curso de Letras).

Os filhos homens são responsáveis pela limpeza do quintal quando moram em casas e, principalmente, do seu quarto, pois o quarto deve permitir, como diz Singly, "a realização de três objetivos: autorizar o filho a ser ele mesmo através de uma autonomia progressiva, oferecer-lhe um quadro de vida encorajando-o ao gosto pelo trabalho e abrir a possibilidade de criar relações com os pais, irmãos e irmãs e com seus amigos" (1998: 99). Assim, Leandro, que trabalha e estuda, diz que a mãe é quem faz todas as tarefas domésticas, mas "ajudo na limpeza do meu quarto, gosto de arrumar do jeito que quero. Não desfazendo da limpeza da minha mãe, limpo mais 'direitinho' porque ela nem é obrigada a limpar corretamente, 
pelo menos o meu quarto" (19 anos, ensino médio, projeto de curso universitário interrompido).

Ele não é o único a justificar a liberação do trabalho doméstico pela falta de tempo: para outros, a jornada diária (trabalho e estudos) e o tempo dos deslocamentos inviabilizam uma ajuda maior em casa. Esta não é uma preocupação para muitos jovens que pertencem às camadas médias, posto que várias famílias têm empregada doméstica ou diarista, como a de Rodrigo, que não mexe uma palha em casa porque

sou filhinho de papai. Sabe aquela relação mágica com as coisas, a roupa limpa, daqui a pouco está suja e depois é guardada na sua gaveta? Na minha casa acontece assim. A gente tem uma empregada que cuida de tudo, que é explorada. Ela faz tudo, não tenho que fazer absolutamente nada (23 anos, estuda psicologia).

Independente de ter ou não quem faça as tarefas por eles, é importante assinalar que a ordem doméstica e suas regras são fruto de intensas negociações entre pais e filhos para ajustar os interesses de cada um. Assim, deixar os objetos pessoais nos espaços comuns contraria a ordem materna e, consequentemente, gera conflitos e negociações (Ramos, 2006).

\section{Autônomos e dependentes: o apoio parental}

Os trabalhos que abordam os ritos contemporâneos da passagem à idade adulta $^{14}$ assinalam que o prolongamento dos estudos e o tempo para a inserção profissional contribuem para a permanência mais longa dos filhos na casa dos pais. São, desta forma, razões financeiras, e os motivos que frequentemente promovem a decoabitação ${ }^{15}$ mais cedo costumam ser: estudar ou trabalhar longe de casa e sair para viver conjugalmente.

Poucos são os que ainda vivem na casa paterna e que não estudam. Esta é, talvez, a razão da permanência - seus projetos profissionais são valorizados pelos pais. Isto não significa que eles não evoquem o desejo de independência com a saída definitiva da casa paterna. ${ }^{16}$ Enquanto esperam, recebem múltiplos apoios materiais dos pais: moradia e alimentação, transporte, despesas escolares e pequenos lazeres. Quanto aos apoios afetivos, eles se distribuem entre o incentivo aos estudos, a elaboração das tarefas domésticas que seriam de seu encargo, as conversas e o aconselhamento. Nas famílias cujos pais são casados, fica claro que é o pai quem financia as despesas dos filhos, enquanto o apoio afetivo é dado pela mãe. Se Eduardo diz, sem constrangimento, que o pai é o banco da família e, assim, o responsável pelas 
contas domésticas, a compra de livros e o transporte que usa para se locomover, Rodrigo parece bastante desconfortável em ser dependente dos pais:

Sempre me incomodou. É horrível o momento em que ele me dá a grana. Ele não tem obrigação nenhuma, tenho 23 anos! Eu me cobro muito isso, apesar de achar que sou muito novo. Mas aquele momento da grana acho constrangedor demais, prefiro quando não estou e ele deixa em casa.

Os jovens consideram essas ajudas fundamentais para permanecerem estudando; vários insistem em que o papel dos pais é investir nos seus projetos para o futuro para que conquistem autonomia e independência financeira. A contrapartida desse investimento é a cobrança do tempo dedicado aos estudos e seus resultados, o que pode gerar conflitos entre eles, pois os jovens se consideram autônomos ${ }^{17} \mathrm{e}$ contestam o controle dos pais. Leandro fala da pressão parental, ainda que tente justificá-la: "O fato de eles me pressionarem muito não considero errado, porque se eles não fossem assim, eu também não seria quem sou hoje, tenho orgulho deles". Como aponta Cicchelli,

muito insistente, o apoio pode ser visto como uma ingerência; muito frouxo, pode ser percebido como uma manifestação de indiferença. A práxis e a hermenêutica parentais devem oscilar entre estes dois polos: interpretar para intervir, intervir para apoiar, eis o apelo, a espécie de double bind que os jovens dirigem a seus pais para que sua associação se torne vantajosa para o bom desempenho nos estudos (2000: 118).

É importante ressaltar que os apoios visam à realização do projeto individual dos filhos. Nesse sentido, pais e filhos valorizam esse período de estudos universitários ou técnicos como fundamental para melhor qualificação profissional. Kellerhals et al. assinalam que

os referenciais familiares, outrora articulados em torno de afiliações e de pertenças (a família participava na construção de uma identidade social, dada a sua faculdade de vincular os indivíduos aos grupos que constituem o seu meio social), passam a estar, ao longo do tempo, mais centrados nas capacidades individuais de desenvolvimento de recursos pessoais destinados à inserção no espaço social de acordo com projetos pessoais (2002: 565).

Nem todos os jovens foram influenciados pelos pais na escolha profissional, como Viviane e Eduardo: ela fez psicologia e agora cursa letras - "a identificação 
com a minha mãe deve ter me levado a fazer psicologia"; ele relutou, mas acabou estudando engenharia como o pai: "a decisão pela engenharia é recente... eu tinha várias dúvidas. [O projeto] é me formar em engenharia e trabalhar com meu pai. Ele acha isso ótimo, porque sempre foi o que quis".

Há pais e filhos que consideram que o diploma universitário deixou de ser um fim para se tornar um meio no processo de profissionalização pois, em algumas carreiras, ele não é mais garantia de inserção imediata no mercado de trabalho, há que prosseguir os estudos para a obtenção de títulos mais elevados e de especializações mais pontuais. Os jovens adiam desta forma o projeto de independência, prolongando a permanência na casa paterna. Lourenço e Eugênia cursam a pós-graduação, recebem bolsas de estudo e ainda necessitam do apoio material familiar. Optaram por estudar em outra cidade e, assim, poder administrar suas vidas com mais autonomia. Já Viviane aceita melhor a ingerência da mãe no seu projeto profissional: "Depois do mestrado, quando estiver trabalhando e ganhando uma grana legal, pretendo sair de casa. Minha mãe fala que não faz sentido eu abandonar meus sonhos para sair de casa. Ela quer que eu siga a carreira acadêmica, para isso preciso me dedicar”.

O caso de Patrícia (20 anos, universitária) parece muito particular, pois recebe bolsa de estudos exígua e ainda assim custeia todas as suas despesas escolares, de transporte e lazer. Mesmo que tenha "perdido as expectativas de tudo, porque a gente vê que a faculdade também não garante nada”, ela é pressionada pelos pais para trabalhar e sair de casa:

Eles acham que tenho que terminar esse curso e também arrumar um emprego, porque a situação está difícil em casa e eles não podem bancar a faculdade para mim. Eles me apoiam para não desistir, porque não tiveram esta oportunidade, mas meu pai me pressiona para sair de casa, seguir minha vida, sair logo de lá.

Os apoios afetivos se traduzem em estímulos para estudar, na preparação de lanches e em conversas sobre a vida profissional, pessoal e mesmo amorosa. Este seria o papel das mães, mas vários jovens o dispensam dizendo que não têm tempo para conversar, principalmente sobre a vida amorosa. As questões profissionais são mais facilmente abordadas pelos pais, que parecem cobrar mais empenho dos filhos nos estudos ou desconsiderá-los, como o pai de Patrícia: "converso mais com minha mãe, porque meu pai acha que sou meio burra”.

Em sua pesquisa, Cicchelli também identificou o limite entre as questões compartilhadas com os pais e aquelas de foro íntimo: "a ingerência só se refere ao campo autorizado: os estudos. Eles protegem ciosamente os outros territórios para que 
os pais não façam do acompanhamento escolar um meio para invadir o resto de suas vidas" (2000: 122). Se conseguem construir barreiras para impedir o acesso à vida íntima, elas são ineficazes no campo dos estudos. Muitos são os pais que cobram o retorno desse investimento, nem que seja para ver o material adquirido e os livros comprados, como o pai de Rogério, que solicita os comprovantes das compras: "quem compra sou eu, com o dinheiro deles [...] Claro que no final eles querem ver o que comprei: nota fiscal com dia, hora, controlam direitinho".

Os jovens cujos pais são separados ou viúvos (7) em geral moram com as mães, que são responsáveis pelos apoios material e afetivo. É possível, então, compreender a ingerência da mãe de Viviane nas decisões sobre a sua formação: "minha mãe banca tudo. Agora que não estou ganhando nada, ela me banca em tudo”.

\section{A (im)possibilidade de conciliar trabalho e estudo}

Os processos de construção dos projetos de futuro estão relacionados às condições sociais, mas também às suas práticas cotidianas (contextos familiares, grupos de amigos etc.) que tendem a influenciar as suas decisões (Pais, 1996). Se Eugênia e Viviane, ${ }^{18}$ cujos pais têm diplomas universitários, afirmam nunca terem pensado em não cursar a universidade, pois "desde pequena já era certo eu fazer a universidade, como minha mãe" (Viviane), Adalberto ${ }^{19}$ e Rogério, ${ }^{20}$ filhos de pais que não concluíram o curso fundamental, criaram expectativas de ascensão familiar com o ingresso na universidade:

Eles ficaram bem felizes quando consegui passar para a faculdade e muito orgulhosos, porque eles são de família humilde e não tiveram oportunidade na roça. E agora veem um filho na faculdade... (Adalberto, o pai é bombeiro hidráulico).

Como eles têm uma escolaridade muito baixa, na minha família são poucos os que têm ensino superior, então eles acharam aquilo maravilhoso! (Rogério, o pai é operário da construção civil).

Os jovens recebem ajuda dos pais para construir seus itinerários profissionais, através do interesse pelo que estudam, pelas escolhas que fizeram e dos inúmeros apoios de ordem afetiva e material. O apoio parental é um investimento mútuo de pais e filhos na formação profissional destes. Contudo, nem todos podem contar com o apoio material sistemático dos pais, principalmente se pertencem às camadas populares; eles apoiam até os filhos completarem o ensino médio, quando já podem começar a trabalhar exercendo atividades nos setores industriais ou de 
serviços. Adalberto fez capacitação técnica e abandonou a faculdade de administração para trabalhar:

Meus pais são humildes, trabalharam em roça muitos anos e vieram para o Rio trabalhar na cidade grande, em busca de melhores recursos. A gente mora em uma comunidade e vi a necessidade de trabalhar devido às dificuldades que eles passavam. Eles sempre me deram roupas, ajudavam no estudo, mas chegou uma hora em que tive que procurar um trabalho para poder me manter e ajudar eles no possível (26 anos, operário de indústria petroquímica).

O percurso de Alessandra (23 anos) é semelhante, pois decidiu abandonar o estudo formal e buscar outras capacitações para trabalhar na indústria, à espera de um melhor momento para sair da casa da mãe: ${ }^{21}$

Comecei a cursar inglês, mas surgiram alguns problemas financeiros e não deu para continuar, está trancado. O de informática tranquei também, mas o trabalho exige uma noção de inglês e de informática. No mercado de trabalho, quanto mais curso você tiver, quanto mais se aprimorar, melhor. [...] Eu tinha a expectativa de que o mercado seria mais amplo e, quando saí do segundo grau, vi que não é bem isso. A escola não disponibiliza estágio, a gente sempre tem que correr atrás, por causa desse processo vi que as coisas não eram fáceis.

Antônio (20 anos) pretendia cursar engenharia química: fez o vestibular três vezes e não passou. Não desistiu e, enquanto se prepara para nova tentativa, faz "cursos de informática, de agente de segurança, e aprendi inglês por conta própria. São atividades necessárias para arrumar um bom emprego, dão certo diferencial”.

Já Felipe (18 anos), saiu da casa dos pais ${ }^{22}$ antes de terminar o ensino médio, porque decidiu entrar para a Companhia Étnica de Dança

[Queria] dançar muito, subir em palcos profissionais, rodar o país e o mundo dançando, fazendo o que gosto [e os pais não concordaram]: meu pai queria que eu seguisse a carreira militar e a minha mãe também. Para eles, o que dá dinheiro é o militar, dança não dá dinheiro, dança não dá futuro.

Foi acolhido temporariamente pela mãe de um amigo e, em contrapartida, ajuda nas tarefas domésticas. Não volta mais para a casa da mãe: 
[...] foi uma briga muito ruim. A minha mãe é muito preconceituosa, não aceita a Companhia, não aceita meus amigos. Para ela, eles são "viados" e a Companhia Étnica, sendo do morro do Andaraí, sinal de que vou fumar maconha, vou cheirar... É muito preconceituosa, a gente brigava muito.

Dentre os jovens entrevistados, somente quatro não moram com os pais: um é casado e três moram com amigos ou irmãos. Paulo (27 anos) saiu de casa para viver conjugalmente, abandonando os estudos. Nessa época, estava "desiludido" com o sistema de ensino: "não achei que isso fosse garantir melhor colocação e, além disso, é só para quem tem dinheiro". Desempregado e sem ajuda dos pais (recebe eventualmente da avó), reestrutura sua visão de mundo, incorporando os estudos universitários em seu projeto futuro: "hoje, valorizo mais a formação 'formal', canudo e tudo. Nem acho tão importante, mas o mercado de trabalho valoriza. [Quero] adquirir casa própria, um emprego estável e rentável e que eu goste e, concluir a faculdade...”.

Os motivos do abandono escolar são, em geral, financeiros: alguns o fazem por escolha, desiludidos com a possibilidade de melhor inserção no mercado de trabalho via diploma universitário; outros, por necessidade, em face das precárias condições econômicas familiares que pressionam para o ingresso precoce na vida produtiva. Para estes, pertencentes às camadas populares, não se trata de abandono, mas de uma interrupção até que possam retomar o projeto individual profissional. Mesmo aqueles que abandonaram os estudos para trabalhar o fizeram contra a vontade dos pais.

Se uns abandonam os estudos por necessidade, outros procuram conciliar trabalho e estudo sem interromper o projeto de obter um diploma universitário e, assim, ascender socialmente através de melhor qualificação profissional. Para estes, é grande o desgaste em desempenhar as duas tarefas, tanto pela (in)disponibilidade de tempo para estudar quanto pelo custo financeiro dos estudos (despesas escolares e de transporte). Entre os que já têm alguma atividade remunerada, 14 afirmam ter começado a trabalhar antes dos 18 anos, sete depois dos 20 e já como estudantes universitários recebendo bolsas (pesquisa ou estágio). Estes afirmam que o valor das bolsas é baixo, portanto, os pais continuam apoiando: é "para pequenas coisas e me dá uma grande ajuda, mas eles é que me mantêm na universidade. Esse dinheiro é um extra que gasto com o que bem entendo" (Rogério, 23 anos). O que importa para eles é o sentimento de autonomia, de ter certa independência financeira, ainda que ela seja relativa e efêmera: "um ano sem ter que justificar para que vou gastar aquele dinheiro" (Mônica, 22 anos). 
Já os que têm um trabalho remunerado dizem que começaram a trabalhar para contribuir em casa, aumentando a renda familiar, e pela vontade de ter independência financeira e poder decidir sobre como usar o dinheiro recebido. Leandro (19 anos, pré-vestibular comunitário) conta que ficava atraído pelas propagandas televisivas de roupas e sapatos, querendo comprar os artigos que a moda ditava. ${ }^{23}$ Começou a trabalhar aos 16 anos porque queria ter o que "todo mundo tem e eu não”. Aos poucos percebeu o valor do trabalho e do dinheiro. Antes de se empregar, planejava "encher minha geladeira de maçã, de danoninho, vou encher de besteira"; com os primeiros salários, refez os planos, priorizando outros consumos: "não comprei maçã até agora, comprei minhas coisas: cama, som, vou comprando aos poucos, troquei de celular, roupas para mim. É legal, você dá valor ao seu dinheiro”.

Da mesma maneira que os pais influenciam pouco a escolha da profissão dos filhos, eles interferem menos ainda no destino que estes dão às remunerações que recebem (bolsas ou salário). Poucos são os pais que exigem uma contribuição dos filhos nas despesas familiares. Hoje, a passagem de uma etapa da vida à outra é mais rápida e direta, já que o prolongamento dos estudos e a entrada tardia na vida do trabalho prorrogam o tempo de coabitação com os pais. Isto não impede, contudo, que os jovens sejam autônomos. Assim, a liberdade para construir um projeto profissional e decidir como gastar o dinheiro recebido pelo trabalho realizado é percebida pelos jovens como os primeiros passos para a emancipação completa.

\section{Entre a casa, a escola e o trabalho}

Para a maioria dos jovens que trabalha e estuda, os deslocamentos entre casatrabalho-escola/ universidade são cansativos, posto que os meios de transporte são precários. Felipe usa três ônibus e um trem para se deslocar (só ida) de casa à escola de dança onde trabalha e estuda: são quase duas horas de trajeto. Quando viaja sentado, aproveita para ler, mas quando o transporte está lotado, "não dá muito para estudar". Rogério é outro que mora distante da universidade e, como Felipe, usa trem e ônibus para ir de Guaratiba ao Maracanã: despende duas horas de trajeto, em transporte lotado e desconfortável. João também mora distante (Pedra de Guaratiba), trabalha no Centro da cidade e estuda na zona norte (Maracanã): sai de casa às $5 \mathrm{~h}$ para chegar no trabalho às $8 \mathrm{~h}$ e estuda à noite, retorna por volta de 22h30: é o tempo de jantar, dormir e recomeçar novamente! Já Maria usa ônibus e barca para ir de casa (Benfica) à universidade (Niterói), são duas horas de trajeto e "sai meio caro", porque paga o transporte com a bolsa de estudos.

Os exemplos são inúmeros e o caso de Ruth é o mais impressionante: morava em Belford Roxo ${ }^{24}$ com os pais e despendia tempo (4h por dia) e dinheiro 


\section{Deslocamento dos estudantes da casa para o trabalho, a universidade ou a escola}

\begin{tabular}{|c|c|c|c|c|c|c|}
\hline $\begin{array}{l}\text { Nome do } \\
\text { estudante }\end{array}$ & $\begin{array}{l}\text { Bairro de } \\
\text { moradia }\end{array}$ & $\begin{array}{l}\text { Bairro do } \\
\text { trabalho }\end{array}$ & $\begin{array}{l}\text { Universidade } \\
\text { ou escola }\end{array}$ & $\begin{array}{l}\text { Distância } \\
\text { (só ida) }\end{array}$ & $\begin{array}{l}\text { Meio de } \\
\text { transporte }\end{array}$ & Tempo \\
\hline Felipe & $\begin{array}{l}\text { Ricardo de } \\
\text { Albuquerque }\end{array}$ & Anchieta & Andaraí & $31 \mathrm{~km}$ & trem e ônibus & $2 \mathrm{~h}$ \\
\hline Rogério & Guaratiba & $\longrightarrow$ & Maracanã & $50 \mathrm{~km}$ & $\begin{array}{l}\text { ônibus, trem } \\
\mathrm{e} 2^{\circ} \text { onibus }\end{array}$ & $2 \mathrm{~h}$ \\
\hline João & $\begin{array}{l}\text { Pedra de } \\
\text { Guaratiba }\end{array}$ & Centro & Maracanã & $59 \mathrm{~km}$ & $\begin{array}{l}\text { ônibus, trem } \\
\text { e } 2^{\circ} \text { onibus }\end{array}$ & $2 \mathrm{~h} 20$ \\
\hline Ruth & $\begin{array}{l}\text { Belford } \\
\text { Roxo }\end{array}$ & - & Maracanã & $39 \mathrm{~km}$ & 2 ônibus & $2 \mathrm{~h} 40$ \\
\hline Viviane & Méier & $\begin{array}{l}\text { Ilha do } \\
\text { Fundão }\end{array}$ & Urca & $51 \mathrm{~km}$ & 2 ônibus & $1 \mathrm{~h} 20$ \\
\hline Maria & Benfica & - & Niterói & $18 \mathrm{~km}$ & ônibus e barco & $2 \mathrm{~h}$ \\
\hline Patrícia & Taquara & - & Maracanã & $24 \mathrm{~km}$ & 1 ônibus & $1 \mathrm{~h} 30$ \\
\hline Lourenço & Niterói & & $\begin{array}{l}\text { Ilha do } \\
\text { Fundão }\end{array}$ & $23 \mathrm{~km}$ & 1 ônibus & $1 \mathrm{~h} 20$ \\
\hline Eugênia & $\begin{array}{l}\text { Barra da } \\
\text { Tijuca }\end{array}$ & & $\begin{array}{l}\text { Ilha do } \\
\text { Fundão }\end{array}$ & $31 \mathrm{~km}$ & carro próprio & $30 \mathrm{~min}$ \\
\hline Pedro & $\begin{array}{l}\text { Barra da } \\
\text { Tijuca }\end{array}$ & Centro & Centro & $26 \mathrm{~km}$ & carro próprio & $40 \mathrm{~min}$ \\
\hline
\end{tabular}

(R \$ 190,00) $)^{25}$ para se deslocar até a universidade. Junto com outros colegas que viviam a mesma experiência, alugou um apartamento perto da universidade: sua contribuição para o aluguel é menor do que o custo que tinha com transporte!

A título de exemplo, selecionamos os trajetos de dez estudantes a fim de mostrar que, para quilometragens semelhantes, os tempos dispendidos são mais longos, conforme a oferta e o tipo de transporte público usado.

As despesas de transporte e custos escolares são financiadas parcialmente pelos próprios estudantes através do trabalho (8) ou das bolsas de estudo (10); algumas são bolsas de pesquisa, outras são para alunos cotistas. Muitos desses estudantes 
acreditam ter conquistado certa autonomia e independência, porque administram o que recebem mensalmente. Como disse Daniela, "a partir do momento em que você não tem mais que pedir dinheiro a eles, você pula a barreira de poder sair ou não. Passa a ser 'eu vou!', pois passo a ter o direito de fazer".

O quadro (página anterior) mostra as distâncias percorridas por alguns jovens entrevistados; uns vivem em áreas nobres, outros, em comunidades faveladas. Certos percursos são mais longos que outros, e os tempos de deslocamento variam menos em relação à distância e mais na quantidade e no tipo de transporte utilizado. Os deslocamentos em trem, dada a precariedade da rede férrea, são mais demorados, e as linhas de ônibus que servem à zona oeste são menos frequentes. Assim, certas distâncias com quilometragem aproximada podem ser feitas em tempos muito diferentes, dependendo dos meios de transporte oferecidos. Neste aspecto, os jovens de camadas populares e médias têm a mesma dificuldade de locomoção, salvo os que possuem carro particular. $\mathrm{O}$ mesmo se aplica para os jovens que moram perto da escola/universidade; o que os diferencia é o lugar e as condições da moradia: no asfalto ou no morro.

\section{Considerações finais: aspirações e dificuldades}

Tempo disponível (para os que trabalham) e despesas escolares não são as únicas barreiras para cursar a universidade, apontaram os jovens das camadas populares. A principal delas é o déficit escolar em relação aos demais, o que cria uma desvantagem na aprendizagem e, consequentemente, no concurso para ingresso à universidade. E se, ainda assim, se tornam universitários, outros problemas aparecem. Com escolaridade precária, muito aquém daquela dos jovens das camadas médias que frequentaram as escolas privadas (em geral, de melhor qualidade de ensino) e vivendo em bairros distantes (e em moradias precárias), os jovens de camadas populares têm mais dificuldade para acompanhar as disciplinas, finalizar o curso e obter o diploma universitário.

Outros fatores são as universidades públicas muito distantes da moradia, os longos trajetos percorridos entre casa/universidade - e trabalho para alguns - e o alto custo dos transportes. Além disso, eles não têm meios para adquirir livros e as bibliotecas nem sempre dispõem de vários exemplares de uma obra. Lê quem chega primeiro. Maria relata as dificuldades que enfrenta para estudar, não só porque em casa divide o quarto com a mãe e não tem livros, como também nem sempre consegue na biblioteca universitária um exemplar:

Falta grana pra livro. Está muito caro e a gente xeroca aquilo que deveria ter na estante: o livro inteiro. A gente acaba fragmentando tudo, às vezes rola dificul- 
dade até para o xerox, tem a biblioteca, mas aí nem livro nem xerox! A grana da bolsa é patética! Uma ajuda de custo que só dá para a metade do mês. Se for contar na ponta do lápis todo o gasto, a bolsa é uma piada! (22 anos, universitária).

Já Daniela (20 anos) trabalha o dia inteiro e cursa a universidade à noite. Como não para em casa, procura estudar no próprio trabalho: "em casa, só mesmo na semana de provas, quando me tranco no quarto e peço para ninguém abrir a porta". O esforço vale a pena, pois sempre sonhou entrar para a universidade. Não se classificou na universidade pública, mas sim na privada, e "foi como ganhar o Oscar, uma grande medalha. O meu esforço, a minha luta, tudo meu!”. Ela trabalha para pagar a universidade, já que a mãe, viúva, é vendedora de material elétrico.

Para as camadas superiores, o diploma universitário faz parte da trajetória dos filhos, enquanto para os pais das camadas populares ele significa uma ruptura das trajetórias familiares das gerações precedentes (Ferrand, 2001). Como a vontade de ser universitário é cada vez maior entre os jovens de baixa renda, o ensino superior brasileiro tem sido ampliado de forma abrupta, sobretudo depois da implantação das políticas de inclusão social (cotas) para os estudantes negros e os egressos de escolas públicas (Schwartzman 1994, 2004). ${ }^{26}$ Logicamente esta motivação encontra respaldo nas exigências do mercado de trabalho que valoriza cada vez mais os diplomas universitários. Roberta (25 anos), cujos pais têm diploma de nível superior, abandonou a universidade para trabalhar porque não valorizava o diploma. Rápido entendeu que "se tivesse curso superior, por mais que não tenha nada a ver com o que trabalho, ganharia mais. E poderia ganhar outros cargos, como de gerência, poderia subir”.

A procura de aprimoramento leva os jovens a prosseguirem os estudos, cursando pós-graduação strictu senso ou lacto senso, ou cursos de aperfeiçoamento. Se até recentemente o perfil da pós-graduação brasileira era delineado por estudantes das camadas médias, hoje esta tendência diminuiu com os programas de inclusão social e a ampliação de bolsas de estudo, permitindo o acesso dos jovens de camadas populares. ${ }^{27}$ Mônica, cujos pais não terminaram o curso fundamental, estuda enfermagem e projeta o futuro: "não tem como parar de estudar, porque na minha área preciso estar sempre atualizada: lido com pessoas. Assim, quando você tem um conhecimento ultrapassado, pode ser fatal. Quero fazer mestrado e doutorado".

Já Alessandra ${ }^{28}$ se preparou para trabalhar na indústria cursando técnica de eletromecânica: é operadora de processo petroquímico e não pretende sair da empresa onde trabalha, embora preferisse o diploma de gastronomia. Nos discursos dos jovens menos favorecidos, os sonhos e as idealizações do futuro se deparam com múltiplas dificuldades e, por isso, constroem seus projetos profissionais por etapas, sendo o curso de nível médio (técnico ou artístico) uma etapa importante 
a conquistar. Os jovens de camadas médias têm seus itinerários traçados pelos pais até a universidade; resta-lhes o direito à escolha do campo profissional. Raros são os que abandonam a universidade antes de concluí-la, como acontece frequentemente com jovens de baixa renda.

Independente da classe social, o que une esses jovens é a construção de um projeto para o futuro, mas também a incerteza em relação à inserção no mercado de trabalho. O que os distancia é a possibilidade (dos mais favorecidos) de permanecerem mais tempo no sistema escolar apoiados pelos pais e, com isso, adquirirem níveis mais altos de qualificação profissional.

12 Idades de referência para integralização do ensino médio (17/18 anos) e da pós-graduação (mestrado, doutorado, 25/27 anos).

\section{Notas}

* Pesquisa realizada com oito estudantes de Ciências Sociais da UERJ, sob minha coordenação. São eles: Adriana Lima, Eduardo Ribeiro, Isis Martins, Julio César Ferreira, Kelly Santos, Mariana L. Rodrigues, Margareth Mendes, Paulo Tavares.

1. Noção de autonomia inspirada em Singly (2007), que considera haver na família contemporânea uma autonomia crescente do indivíduo em relação à parentela e às gerações mais velhas, pois seus membros têm uma individualidade maior do que nos modelos familiares existentes anteriormente.

2. As políticas educacionais dos últimos anos, sobretudo no que se refere à ampliação e à equalização das condições de acesso e permanência nos níveis de ensino não-obrigatórios, têm focalizado mais nos jovens através da melhoria dos processos de gestão e coordenação das diversas ações implementadas.

3. A Lei de Diretrizes e Bases da Educação Nacional explicita que o ensino médio é a etapa final da educação básica (Art.36). Ao completarem esse nível, os jovens perfizeram 11 anos de estudo e têm aproximadamente 17 anos. Seguindo esse percurso, sem interrupção ou repetição de série escolar, aos 18 anos o jovem entra na universidade, sendo 24 anos a idade máxima de conclusão dos cursos mais longos do nível superior.

4. Há nas comunidades faveladas do Rio um crescimento acelerado de ONGs voltadas para a formação de jovens carentes nas áreas esportiva, de dança e teatro, de fotografia e cinema.

5. Ver o quadro sobre aspectos metodológicos.

6. Alguns desses jovens ingressaram posteriormente na universidade.

7. Fenômeno semelhante nas demais cidades brasileiras: mais de $80 \%$ da população brasileira vivem hoje em área urbana. 
8. O município do Rio tem 5.851.914 habitantes e 1.106.011 vivem em áreas faveladas (IBGE, 2000).

9. Termo empregado pelos moradores de favelas para se referirem ao lugar de moradia por ser menos estigmatizante. O interesse dos moradores em criar Centros de Memória e em buscar a origem das próprias comunidades traduz um processo de ressignificação em que a preservação do termo favela ganha outra dimensão para as próprias comunidades. Agradeço esta observação à Helena Bomeny.

10. Os bairros da zona sul cresceram na planície mais valorizada pela proximidade ao mar, e as favelas se formaram nas montanhas limítrofes, espaço até então desvalorizado. O mesmo fenômeno aconteceu na zona norte, cujos bairros de camadas médias ficam na planície e as favelas nas montanhas. Mas é na área central da cidade que esses setores representam a maior fatia da população total: $28,7 \%$.

11. Idades de referência para integralização do ensino médio (17/18 anos) e da pós-graduação (mestrado, doutorado, $25 / 27$ anos).

12. Assinalamos que somente $3,43 \%$ dos brasileiros possuem curso superior completo, dentre eles, as mulheres são maioria: 54,3\%. Ressaltamos que nesta pesquisa nem todos os pais pertencentes às camadas médias têm diploma universitário.

13. O pai está desempregado desde 1999 e a mãe trabalha num abrigo para crianças deficientes, eles recebem ajuda material da avó paterna. Sobre solidariedade entre gerações (avós \& netos e pais aposentados \& filhos desempregados), ver Peixoto 2000, 2004, 2007.

14. Bozon, 1993; Galland, 1997; Cicchelli, 2001; Ramos, 2006; Pais, 1996, para citar apenas alguns.

15. Godard e Blöss (1988) usam o termo decoabitação para designar a saída definitiva da casa dos pais.

16. Na França, só 9\% dos homens e 7\% das mulheres entre 19-27 anos evocam o desejo de independência financeira como um motivo para sair definitivamente da casa dos pais (Ramos, 2006).

17. Autonomia nem sempre significa independência financeira, pois os jovens têm autonomia para fazer suas escolhas afetivas e profissionais, ainda que dependam do apoio material dos pais.

18. Ambas têm 24 anos e fazem pós-graduação em engenharia e graduação em psicologia, respectivamente.

19. 26 anos, curso de Administração em universidade privada, abandonado por não ter condições de pagar.

20. 24 anos, estuda Letras em universidade pública, tem bolsa de estudos.

21. Mora com a mãe e a filha de 3 anos. Os pais são separados e ela é mãe solteira.

22. Pai desempregado, em tratamento contra drogas, mãe servente em livraria. 
23. Pai copeiro em restaurante, mãe lavadeira.

24. $35 \mathrm{~km}$ da cidade do Rio de Janeiro.

25. Salário mínimo R \$240,00, em 2004, ano das entrevistas.

26. Novas políticas públicas visam à ampliação de oportunidades de acesso à educação superior através de ações afirmativas destinadas a garantir condições de ingresso e permanência desses jovens na universidade: ENEM, ProUni, ampliação do Fies e expansão das Ifes.

27. Sobre a pós-graduação Lato Sensu, ver Oliveira (1995) e Pinto (2000).

28. 22 anos, mãe solteira, pais separados, e residente em bairro popular. 


\section{Referências bibliográficas}

BOZON, Michel. 1997. "Des rites de passage aux 'premières fois'. Socio-ethnologie des rites de la jeunesse en France”. In : DESDOUITS, A-M. \& TURGEON, L. (orgs.). Ethnologies francophones de l'Amérique et d'ailleurs. Québec: Les Presses de L'Université du Laval.

CASTRO, Jorge Abrahão; AQUINO, Luseni Maria C. \& ANDRADE, Carla Coelho (orgs). 2009. Juventude e políticas sociais no Brasil. Brasília: Ipea.

CICCHELLI, Vincenzo. 2000. "Individualismo e formas de apoio: entre lógica incondicional e personalização da parceria intergeracional”. In: PEIXOTO, Clarice; SINGLy, François \& Cicchelli, Vincenzo (orgs.). Família e Individualização. Rio de Janeiro: Ed. FGV. pp. 113-132.

2001. "Repensar os laços entre pais e jovens adultos fora da aporia conflito/entendimento”. Interseções: revista de estudos interdisciplinares, 2(3):247-265.

DAMATTA, Roberto. 1987. A casa e a rua. Rio de Janeiro: Ed. Guanabara.

FERRAND, Michèle. 2001. “Famílias e educação dos filhos na França”. Interseções: revista de estudos interdisciplinares, 2(3):181-197.

GALLAND, Olivier. 1997. Sociologie de la jeunesse. Paris: Armand Collin.

GODARD, F. \& BLÖSS, Thierry. 1988. "La décohabitation des jeunes". In : BONVALET, Catherine (org.). Transformation de la famille et habitat. Paris: PUF/INED.

FOUGEYROLLAS-SCHWEBEL, Dominique. 1994. "Formas de família e socialização - novos desafios”. Revista Estudos Feministas, 2:336-346.

HEILBORN, Maria Luiza. 2006. "Experiência da sexualidade, reprodução e trajetórias biográficas juvenis”. In: HEILBORN, Maria Luiza; AQUINO, Estela; BOZOn, Michel \& KNAUTH, Daniela. O aprendizado da sexualidade. Reprodução e trajetórias sociais de jovens brasileiros. Rio de Janeiro: Garamond 
. 1995. "Gênero: uma breve introdução". In: Gênero, desenvolvimento institucional e ONGs. Rio de Janeiro: Instituto de la Mujer/IBAM. pp. 9-14.

KELLERHALS, Jean, FERREIRA, Cristina \& PERRENOUD, David. 2002. "Linguagens do parentesco: lógicas de construção identitária”. Análise Social, Lisboa, XXXVII (163):545-567.

OLIVEIRA, F.B. de. 1995. Pós-Graduação: Educação e Mercado de Trabalho. Campinas: Papirus.

PAIS, José Machado. 1996. Culturas Juvenis. Lisboa: Imprensa Nacional da Casa da Moeda.

PEIXOTO, Clarice E. 2004. "Aposentadoria: retorno ao trabalho e solidariedade familiar”. In: . (org.). Família e Envelhecimento. Rio de Janeiro: Ed. FGV. pp. 57-84.

. 2000. "Avós e netos na França e no Brasil: a individualização das transmissões afetivas e materiais”. In: PEIXOTO, Clarice; SINGLY, François \& CICCHELLI, Vincenzo (orgs.). Família e Individualização. Rio de Janeiro: Ed. FGV. pp. 95-112.

\& LUZ, Gleice Mattos. 2007. "De uma morada à outra: processos de re-coabitação entre as gerações”. Cadernos Pagu, 29:171-191.

PINTO, H.F. 2000. Educação, Qualificação e Trabalho: As Formas de Inserção da Pós-Graduação Lato Sensu nas Trajetórias Escolar e Profissional. Dissertação de Mestrado, Universidade Federal do Espírito Santo.

RAMOS, Elsa. 2006. “As negociações no espaço doméstico: construir a 'boa distância' entre pais e jovens adultos 'coabitantes"”. In: LINS de BARROS, Myriam (org.). Família e Gerações. Rio de Janeiro: Ed. FGV. pp. 39-65.

SCHWARTZMAN, Simon. 1994. "Ensino superior no Brasil: Tradição e Modernidade". Revista da USP, 8:33-38.

2004. "Equality, Quality and Relevance in Higher Education in Brazil”. Annals of the Brazilian Academy of Sciences, 76(1):173-188. 
SINGLY, François de. 1998. Habitat et relations familiales. Paris: Plan Urbanisme, Construction et architecture.

2007. Sociologia da família contemporânea. Rio de Janeiro: Ed. FGV. 


\section{Resumo}

Este artigo compara as trajetórias de jovens estudantes das camadas populares e médias do Rio de Janeiro, visando entender os processos de autonomia parental. Para a maioria deles, os estudos universitários estão associados à conquista de independência financeira familiar, mas para alguns é a possibilidade de uma ascensão social. Dentre as enormes dificuldades que enfrentam para se manter nas universidades, as principais são: a) o déficit escolar em relação aos jovens das camadas médias e superiores, o que leva a uma enorme defasagem na aprendizagem; $b$ ) as universidades públicas ficam longe de seus domicílios e o custo dos transportes é muito alto; c) as condições de moradia são precárias e eles não têm meios para comprar livros, sendo algumas bibliotecas precárias. Apesar das dificuldades de acesso ao sistema universitário, ele ainda é considerado um dos principais meios para se obter melhor inserção no mercado de trabalho. Contudo, muitos são os jovens que procuram outras formações de nível técnico, artístico ou esportivo. Analisaremos as diferentes estratégias desses jovens para continuarem os estudos e construírem a autonomia e a independência financeira.

\section{Palavras-chave}

Trajetórias juvenis, segregação espacial \& juventude, processos de autonomização familiar

\section{Abstract}

Young Brazilians' transition to autonomy may follow varied paths across social class, and many are the strategies to turn oneself independent from one's family. In spite of difficult access to university, upper education is highly valued as it is supposed to protect from the hazards of labour market. Students are not only interested in post graduation, but also in shorter course, for instance in vocational, sport, or artistic tracks. For most students from working class families, studying at university is still considered a passport to social achievement. This paper concentrates on the huge difficulties these students have in going on with their university studies. Several factors are considered: a) Their poor secondary school experience, compared with middle and upper class students, brings about huge gaps in training; b) Public universities are located quite far from the places where they live, in the centre of the city, and cost of transport is very high; c) Their housing conditions are poor, they can't afford buying books and university libraries are poor. The paper describes the strategies and the steps these students take in order to go on with their studies and build their autonomy.

\section{Key words}

Young people's trajectories, spatial segregation and youth, transition to adulthood 